\title{
Giant cell tumour of the sphenoid bone with dural extension
}

\author{
S A M U E C . OH A E G B L A M A D INDU M. G U P T \\ From the Neurosurgical Unit, Department of Surgery and Department of Morbid Anatomy, \\ University of Nigeria Teaching Hospital, Enugu, Nigeria
}

SUMMARY A case of giant cell tumour of the sphenoid bone is reported. Besides the familiar presentation with headaches, ocular manifestations, and upper cranial nerve lesions, this case showed previously undescribed features such as grand mal seizures, hemiparesis with facial palsy, and dural extension. The reported high incidence in females is questioned. The tumour histologically showed some cartilage.

The rarity of giant cell tumours of the sphenoid bone has been emphasised by previous authors, (Echols, 1945; McNerney, 1949; Handousa, 1951; Ramamurthi et al., 1955; Kanaka et al., 1966). Giant cell tumours of bone (osteoclastomas) are believed to arise from non-osteogenic stromal cells of the bone marrow near the epiphysis. Most of them are found in the epiphyseal region of long bones. Smaller bones like those of the hand and foot, ribs, mandible, scapula, and the vertebrae, may also be the seat of this tumour. Giant cell tumours are very uncommon in the head and, when they occur, they tend to show predilection for the mandible and the maxilla (Geshickter and Copeland, 1949). The case we are reporting here is the sixteenth so far published in English literature.

\section{Case report}

\section{HISTORY}

A 25 year old male patient was referred to the University of Nigeria Teaching Hospital complaining of headaches, blurring of vision, pain in the left eye, and heaviness of his right limbs. The patient first developed left hemicranial headaches about eight months before his presentation to the hospital. These were later associated with nausea and vomiting. Several weeks after the onset of the headaches, he complained of blurring of vision and pain in the left eye. Then he noted heaviness and clumsiness of his right limbs. Two months before admission he experienced definite weakness

Accepte1 2 March 1977 of the right half of his body. For several months, he had exhibited episodes of confusion, and he had had several grand mal epileptic attacks. On admission to hospital, he was so drowsy and con-o fused that he could not tell his own story.

EXAMINATION

There was a conspicuous prominence of the left temporal region. He was drowsy, confused, and dysphasic. His vision was about $6 / 36$ on the right side, and he could only count fingers with the left eye. He had bilateral papilloedema which was more severe on the left side. The left pupil was slightly dilated and sluggish in reaction. There was supranuclear 7 th cranial nerve palsy on the right side and slight impairment of hearing on the left side. He had a right spastic hemiparesis with exaggerated reflexes and an equivocal plantar response. Romberg's test was positive, and the patient tended to fall to the right side.

\section{INVESTIGATION}

Routine urine, stool, and blood analysis were normal. Serum calcium was $2.45 \mathrm{mmol} / 1(9.8 \mathrm{mg} / \mathrm{dl})$. Radiology of the skull showed destruction of the sella turcica and rarefaction of the left temporal bone (Fig. 1). Left carotid angiography showed displacement and stretching of the middle cerebral artery consistent with a temporal space occupying lesion. A tumour blush was also visualised (Fig. 2).

\section{TREATMENT}

The left external carotid artery was ligated in the neck before a left fronto-temporal craniotomy was performed to expose an extradural fleshy, 


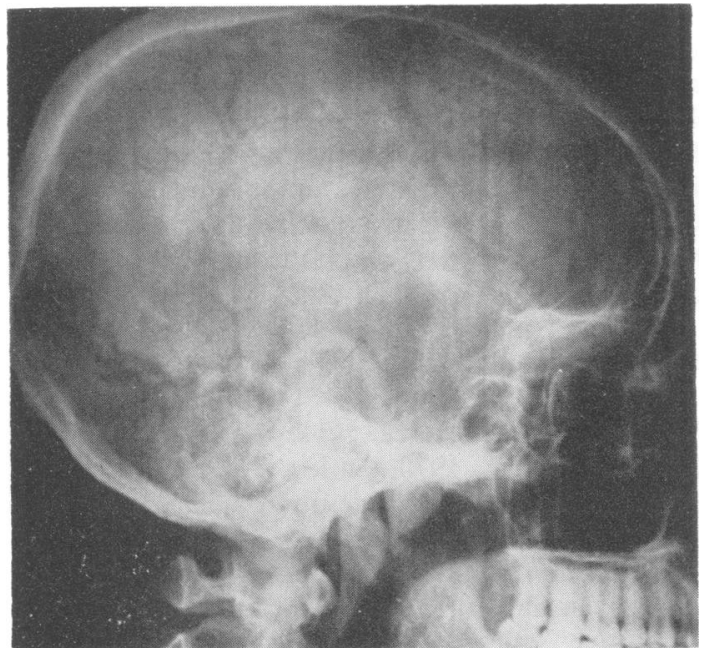

Fig. 1 Lateral radiograph of the skull showing destruction of the sella turcica.

vascular tumour in the region of the sphenoid ridge. The intracranial part of the tumour was excised but it became obvious that complete removal would be impossible as the tumour extended medially to the body of the sphenoid bone. It was also invading the dura mater adjacent to the tumour. The dura mater which was infiltrated by the tumour was excised. In the postoperative period, there was complete neurological recovery and the patient was ambulatory and asymptomatic The patient was advised to undergo radiotherapy in view of the pathological diagnosis of giant cell tumour of the sphenoid, and was discharged home two weeks after surgery on anticonvulsant therapy. However, the patient only resorted to radiotherapy eight months later. At the completion of the course of radiotherapy in another hospital, he had an attack of grand mal epilepsy. Nine months later, he was readmitted to our hospital and was still found to have no neurological deficit and to be asymptomatic. He has been followed up for one year and has remained the same.

PATHOLOGICAL EXAMINATION OF THE TUMOUR The excised tumour consisted of several irregular greyish pieces of tissue with tiny gritty areas. In two bits, dura mater could be identified on gross inspection. Microscopically, the tumour showed a uniformly similar picture of tumour giant cells with abundant stromal cells, many of them in mitosis. Spicules of destroyed bone were evident in between. The tumour was richly vascularised

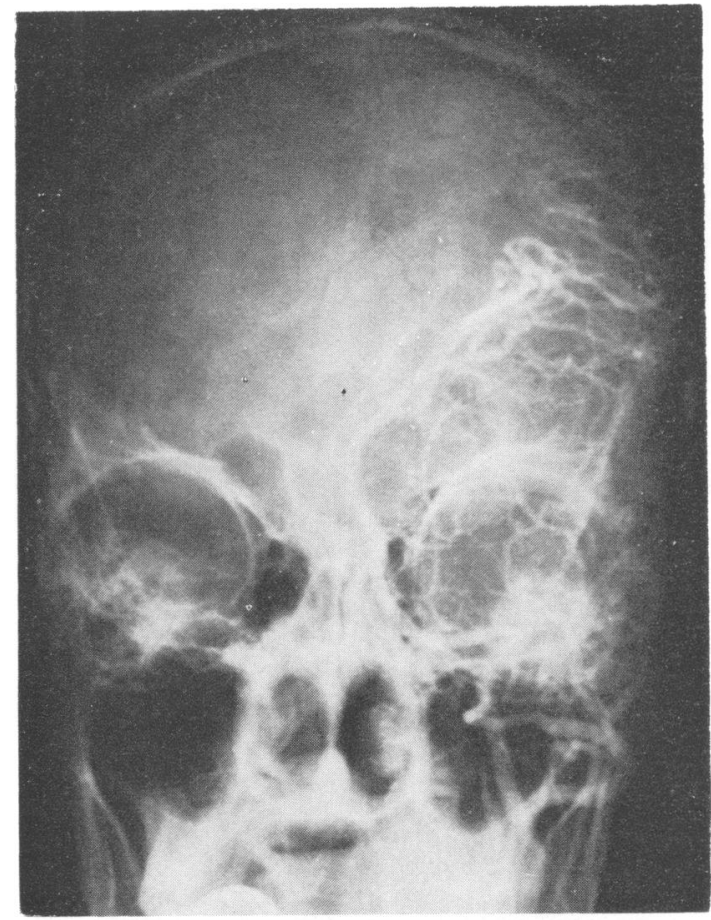

(a)

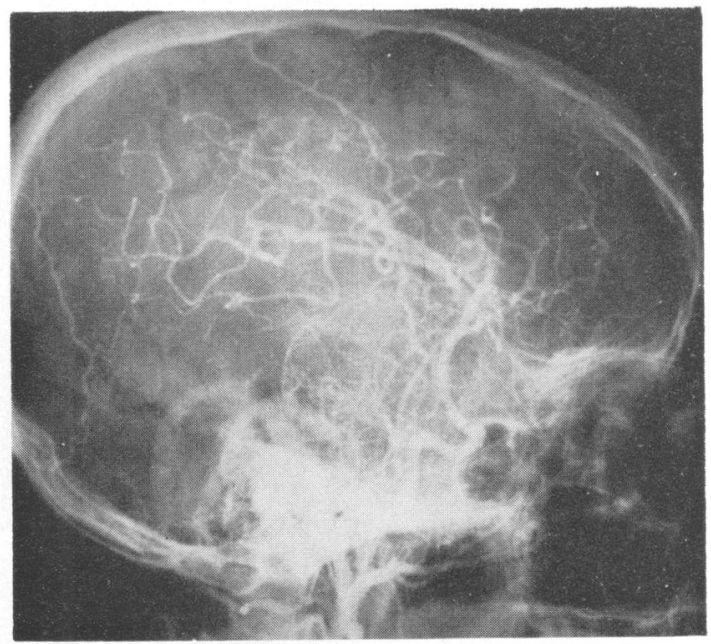

(b)

Fig. (a) AP view of left carotid angiogram showing stretching and medial displacement of the middle cerebral artery. The anterior cerebral artery did not fill. (b) Lateral view of the same angiogram showing stretching of terminal portion of the internal carotid and upward displacement of the middle cerebral artery. A tumour blush is visible in the temporal region. 
and haemorrhagic. In areas adjacent to the thickened collagenous dura mater the tumour giant cells were closely opposed to it and variously

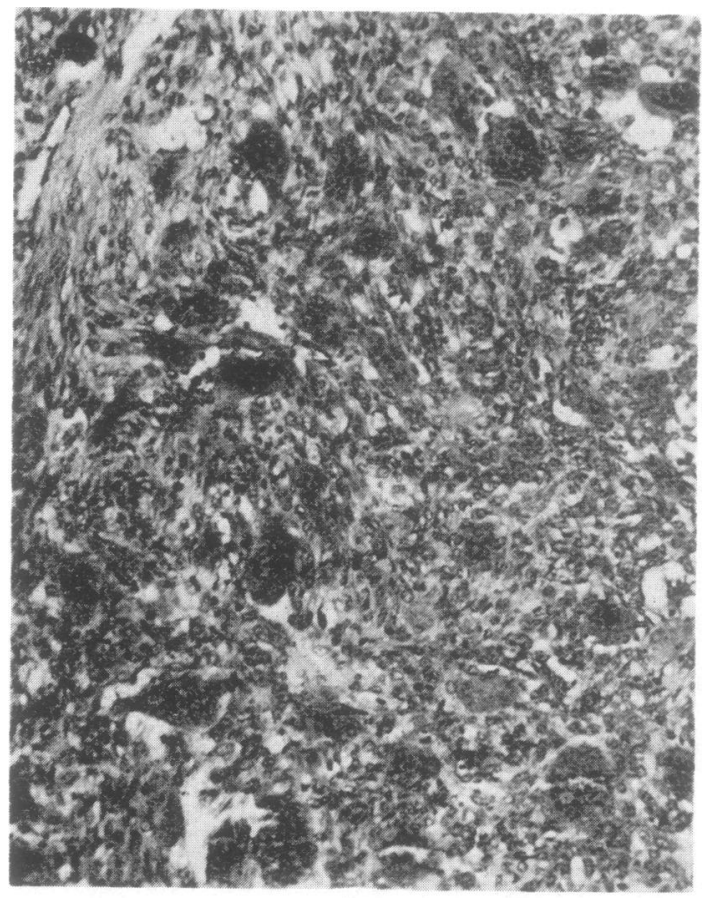

(a) infiltrating it. Considerable hyalinising areas together with areas simulating cartilage with spotty calcification, not unlike those seen in a chondroblastoma, alternated with large areas made up of characteristic giant cell tumour with 'osteoclastic' giant cells throughout the tumour tissue (Fig. 3a, b). In none of the sections were there features of stromal sarcomatous reaction to suggest osteosarcoma.

\section{Discussion}

Previous authors have reviewed the literature (Geissinger et al., 1970; Emley, 1971; Gupta et al., 1975) and have made some observations about the clinical presentation, pathology, and treatment of this tumour. Their conclusions are re-examined here in the light of our present knowledge of this tumour.

AGE AND SEX INCIDENCE

About 10 of the 16 cases so far reported occurred in the second and third decades of life, in agreement with the conclusions of Hutter et al. (1962) who found in their series of 76 cases of benignt $\varnothing$ giant cell tumours of other sites, that the mean age was 23 years. The patient reported here is 25 years old. In 1970, female patients constitutece $72.72 \%$ of the 11 cases reported at that time co (Geissinger et al., 1970). In 1975 (Gupta et al.) that figure dropped to $66.6 \%$. If the case we re

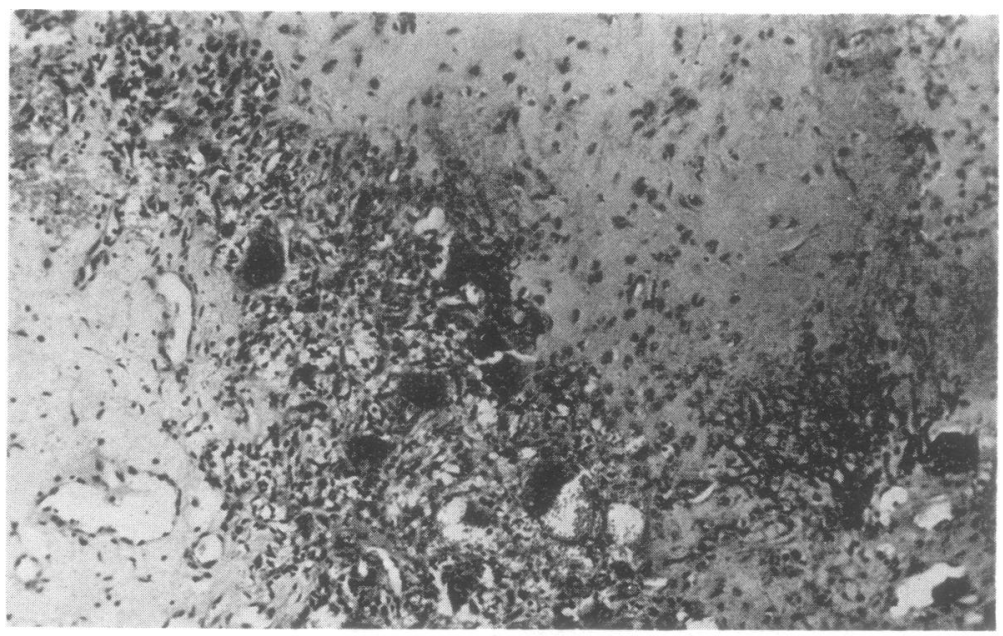

(b)

Fig. 3 (a) Photomicrograph illustrating characteristic giant cell tumour. Note stromal cells with interspersed numerous giant cells. Haematoxylin and eosin, $\times 150$. (b) Photomicrograph showing large hyalinising areas with spotty calcification and giant tumour cells. Haematoxylin and eosin, $\times 150$. 
ported here is included, the female percentage drops to 62.5. It appears, therefore, that the sex incidence is still unknown, and any comparison with the sex incidence of giant cell tumours in general is premature from the limited number of cases so far on record.

\section{CLINICAL PRESENTATION}

Headache and cranial nerve lesions have been common modes of presentation of giant cell tumours of the sphenoid. The headache has tended to antedate other symptoms by several months (Geissinger et al., 1970). Blurring of vision, oculomotor, trochlear, and abducent nerve lesions are other common signs. Trigeminal nerve paresis, proptosis, endocrine disturbances, nasopharyngeal mass, nasal obstruction, nausea and vomiting, retroorbital pain, and olfactory hallucinations have also been reported. Supranuclear facial palsy, hemiparesis, and grand mal epilepsy are additional signs which, to our knowledge, have never been encountered in cases of giant cell tumour of the sphenoid bone. The case reported here is probably the first to show these signs.

\section{RADIOLOGICAL STUDIES}

Plain radiographs of the skull revealed destruction of the sella turcica in almost all cases in which this investigation was carried out including our case. Carotid and vertebral angiography as well as pneumoencephalography were performed in only a few cases, and were reported to have contributed little more than what was already known from the plain skull films. However, in our patient, carotid angiography was very helpful in defining the intracranial part of the tumour, and the information gained was vital in planning therapy.

\section{TREATMENT}

The treatment of this tumour has varied from excision to mere biopsy followed by radiotherapy. Most authors, probably influenced by the good response of the giant cell tumours of long bones and jaw to irradiation (Friedman and Pearlman, 1968), recommend biopsy and radiotherapy in the treatment of giant cell tumour of the sphenoid bone. Although, in most cases, the tumour or part of it is inaccessible for total surgical removal, data so far available permit only cautious optimism about the response of this variety of giant cell tumour to radiotherapy. In the two cases reported by Pitkethly and Kempe (1969), no neurological progression was observed two years and six months respectively after biopsy or partial excision and radiotherapy. Geissinger et al. (1970) reported that their patient, after biopsy and radiotherapy, remained asymptomatic for seven months. Michael (1959) and Eller et al. (1968) reported that after partial excision of tumour and radiotherapy their patients showed recalcification of the sella turcica after four years and three years respectively though cranial nerve palsies persisted. However, the patient reported by Peimer (1954) who underwent radiotherapy after biopsy, had progressive tumour 20 months later. Gupta et al. (1975) reported that their patient at first responded to radiotherapy but three weeks later deteriorated to the extent that surgical excision became necessary. These conflicting results suggest that the natural history of the sphenoid variety of giant cell tumour is yet unknown and is probably different from the giant cell tumour of the long bones and the mandible.

Our patient remained asymptomatic and neurologically normal for eight months after subtotal excision of his tumour before radiotherapy was given. In the absence of neurological deficit, the only index for monitoring his response to this treatment is the state of recalcification of the sella turcica.

\section{PATHOLOGY}

Histologically, giant cell tumours of the sphenoid do not differ in any material way from those encountered elsewhere in the body. Profuse bleeding during biopsy was a feature in an earlier case (Gupta et al., 1975), and also characterised the present one during surgery. A significant point of interest in the present case lay in excluding the theoretical possibility of giant cell tumour arising from dura mater (meningeal), in view of the extensive dural involvement clinically mimicking meningioma. Osteoblastic meningiomas are well known (Russell and Rubinstein, 1971), and when it is considered that dura mater is capable of osteoblastic differentiation in meningiomas, it is conceivable that a tumour of dural origin could differentiate along the line of a giant cell tumour. From the biopsy material alone primary dural giant cell tumour was suspected but was ruled out later from the radiological and operative findings. Russell and Rubinstein (1971) have described a malignant giant cell tumour 'osteoclastoma' of the left parietal region which penetrated the dura mater and adjacent cortex. In none of the giant cell tumours of sphenoid bone previously reported in the literature was there any mention of dural involvement.

Cartilaginous differentiation in the tumour 
tissue is certainly rare and makes one wonder whether the tumour could be categorised as the so-called 'chondromatous' variant of giant cell tumour (Codman, 1931).

The authors gratefully acknowledge the assistance of Dr J. T. K. Duncan, Lagos University Teaching Hospital, Nigeria in carrying out the radiotherapy and $\mathrm{Mr} \mathrm{A}$. Brooks of the University of Nigeria in preparing the illustrations.

\section{References}

Codman, E. A. (1931). Epiphyseal chondromatous giant cell tumours of the upper end of the humerus. Surgery., Gynaecology and Obstetrics, 52, 543-548.

Echols, D. H. (1945). Giant cell tumor of the sphenoid bone-report of a case. Journal of Neurosurgery, 2, 16-20.

Eller, J. L., Deckler, J. T., and Brittis, A. L. (1968). Roentgen therapy for a giant cell tumor of the sphenoid bone. A case report. Radiology Clinics of North America, 37, 36-44.

Emley, W. E. (1971). Giant cell tumor of the sphenoid bone. A case repcrt and review of the literature. Archives of Otolaryngology, 94, 369-374.

Friedman, M., and Pearlman, A. W. (1968). Benign giant cell tumor of bone: radiation dosage for each type. Radiology, 91, 1151-1158.

Geissinger, J. D., Siqueira, E. B., and Ross, E. R. (1970). Giant cell tumors of the sphenoid bone. Journal of Neurosurgery, 32, 665-670.
Geschickter, C. F., and Copeland, M. M. (1949). Tumors of Bone. 3rd Edition, pp. 288-323. J. B. Lippencott Co: Philadelphia.

Gupta, I. M., Gupta, O. P., and Samant, H. C. (1975). Giant cell tumor of the sphenoid bone. Annals of Otology, Rhinology and Laryngology, 84, 359-363.

Handousa, A. B. (1951). Osteoclastoma in relation to the nose. Journal of Laryngology and Otology, 65, 549-559.

Hutter, R. V. P., Worcester, J. N., Jr., and Francis, K. C. (1962). Benign and malignant giant cell tumors of bone: A clinico-pathological analysis of the natural history of the disease. Cancer, 15, 653690.

Kanaka, T. S., and Balasubramaniam, V. (1966). Giant cell tumour of the skull. Neurology (India), 14, $57-60$.

McNerney, J. C. (1949). Giant cell tumor of bones of the skull. Journal of Neurosurgery, 6, 169-174.

Michael, L. A. (1959). Giant cell tumor of the sinuses. Laryngoscope (St Louis), 69, 320-328.

Peimer, R. (1954). Benign giant cell tumors of the skull and nasal sinuses. Archives of Otolaryngology, 60, 186-193.

Pitkethly, D. T., and Kempe, G. L. (1969). Giant cell tumors of the sphenoid. Journal of Neurosurgery, 30, 301-304.

Ramamurthi, B., Visvanathan, G. S., and Pillai, K. M. (1955). Osteoclastoma of the skull. Journal of Neurosurgery, 12, 287-290.

Russell, D. S., and Rubinstein, L. J. (1971). Path ology of Tumours of the Nervous System. 3rd Edition, pp. 60 and 262. Edward Arnold (Publishers) Ltd.: London. 